\title{
Interactions of aluminium hydrolytic species with biomolecules $\dagger$
}

\author{
Received (in Montpellier, France) 31st March 2008, Accepted 12th June 2008 \\ First published as an Advance Article on the web 3rd July 2008 \\ DOI: $10.1039 / \mathbf{b 8 0 5 4 0 6 c}$
}

Olivier Deschaume, ${ }^{a}$ Agathe Fournier, ${ }^{a}$ Kirill L. Shafran ${ }^{a b}$ and Carole C. Perry ${ }^{* a}$

\begin{abstract}
In this contribution the formation of bioinorganic assemblies between the basic globular protein lysozyme and aqueous aluminium species including $\mathrm{Al}_{13}$-mer, $\mathrm{Al}_{30}$-mer and colloidal aluminium hydroxide have been explored and comparison made to previous interaction studies performed with bovine serum albumin (BSA). Specific charge-stabilised bioinorganic assemblies involving aluminium species and lysozyme were observed to form in contrast to the gel like structures formed on interaction of BSA with aluminium species. As demonstrated by infrared spectroscopy (structural assignment, 2D correlation spectroscopy), interactions mostly involve acidic surface groups of the proteins (Asp, Glu), with strong complexation and deprotonation in the case of BSA interacting with $\mathrm{Al}_{13}$ and $\mathrm{Al}_{30}$ and through hydrogen bonding for lysozyme interacting with the same species and aluminium hydroxide particles interacting with both biomolecules.
\end{abstract}

\section{Introduction}

Due to its availability and exceptional properties in both the metallic and ionic forms, aluminium is one of the most important metals for the world economy. Despite its numerous applications in fields such as catalysis, ${ }^{1}$ clay pillaring, ${ }^{2}$ water treatment ${ }^{3}$ and cosmetics, ${ }^{4}$ many domains of aluminium chemistry and biochemistry remain unexplored, mainly due to the formation and complex interrelationships existing between aqueous ionic species or between ionic and precipitated forms of aluminium. ${ }^{5}$

Aluminium ions undergo hydrolysis and condensation reactions in aqueous solution, leading to the formation of a range of species which can be differentiated on the basis of their nuclearity and hydrolysis ratio $\left(h=C\left(\mathrm{OH}^{-}\right) / C(\mathrm{Al})_{\text {total }}\right){ }^{6} \mathrm{~A}$ striking difference between aluminium and other abundant metals such as iron is the high stability of large soluble polynuclear species such as $\mathrm{Al}_{13}$-mer and $\mathrm{Al}_{30}$-mer. ${ }^{7,8}$ Another difference is that aluminium is not essential to life, and can be classified as a detrimental element. ${ }^{9}$

In previous studies, the interactions of aluminium species with biopolymers have focused on monomeric forms of the aluminium $\operatorname{ion}^{10}$ as well as on the adsorption of different ligands on aluminium hydroxide and oxide surfaces, ${ }^{11}$ differentiating between the possible complexes formed with biological ligands and demonstrating the effect of aluminium ions on the biological functions of the biopolymers.

During the last few years, an increasing number of studies have demonstrated the presence of polynuclear aluminium species in the environment ${ }^{12}$ and the toxicity of such species

${ }^{a}$ School of Science and Technology, Nottingham Trent University, Clifton Lane, Nottingham, UK NG11 8NS.

E-mail: carole.perry@ntu.ac.uk; Fax: +44 (0)1158486695;

Tel: +44 (0) 1158486695

${ }^{b}$ Current address, Unilever Research and Development, Port Sunlight, Quarry Road East, Bebington, The Wirral, UK CH63 3JW

$\dagger$ Electronic supplementary information (ESI) available: $\mathrm{pH}$, conductivity and viscosity measurements of the systems at variable protein concentration. See DOI: 10.1039/b805406c has been clearly demonstrated for plant growth. ${ }^{13,14}$ It is therefore necessary to study the interactions of polycationic aluminium species with biological ligands, to identify how protein conformation, stability and charge (and hence their biological function) can be affected by such species; and vice versa, what is the impact of proteins on aluminium speciation?

Our research aims to understand how charge, morphology and the structure of aluminium aqueous species influence their interaction with other molecules such as proteins. This understanding could then be used to emulate biomimetic approaches to the preparation and improvement of aluminium-based materials. ${ }^{15} \mathrm{~A}$ better control and understanding of such materials could minimise risks of release or improper use of harmful forms of the metal. Examples of the undesirable effect of existing materials and substances used include the cases of vaccine adjuvants creating aluminium sensitisation, ${ }^{16}$ or alums used for water treatment that leave traces of monomeric and polymeric aluminium ions in drinking water. ${ }^{17}$

In this study, the interactions of the basic globular protein lysozyme (LSZ, isoelectric point 11.4 ) with $\mathrm{Al}_{13}$-mers, $\mathrm{Al}_{30}$-mers and colloidal hydroxides have been explored for a range of protein : aluminium ratios. $\mathrm{Al}_{13}$-mers and $\mathrm{Al}_{30}$-mers have properties which make them useful as models for the aluminium hydroxide surface and yet can be monitored in solution using ${ }^{27} \mathrm{Al}$ solution nuclear magnetic resonance $\left({ }^{27} \mathrm{Al}\right.$ NMR) and infrared (IR) spectroscopies. The advantage of using colloidal aluminium hydroxide particles lies in the possibility of quantifying parameters such as zeta potential and size, while at the same time taking advantage of the high surface area to maximise the area available for molecular level interaction. ${ }^{11}$ Colloidal, molecular and macroscopic variables have been monitored to study the modification of both inorganic and biomolecular phases. The results obtained have then been compared to the findings of a previous study that focused on the interactions of bovine serum albumin (BSA, isoelectric point 4.75) with a similar range of aluminium species. $^{15}$ 


\section{Experimental}

\section{Stock solutions/model aluminium-protein systems}

Single species systems containing either $\mathrm{AlCl}_{3}, \mathrm{Al}_{13^{-}}$mer, $\mathrm{Al}_{30^{-}}$ mer and an Al hydroxide sol with particles size of $100 \pm 10 \mathrm{~nm}$ were prepared from crystalline $\mathrm{AlCl}_{3} \cdot 6 \mathrm{H}_{2} \mathrm{O}(99 \%$, Fisher Scientific), in distilled deionized water as detailed previously. ${ }^{15}$ The final aluminium concentration in the model solutions was $0.3 \mathrm{~mol} \mathrm{~L}^{-1}$, the purity of the resulting systems being checked by quantitative ${ }^{27} \mathrm{Al}$ solution NMR spectroscopy and a Ferron kinetic assay $\left(\mathrm{Al}_{13}\right.$-mer: $97 \% ; \mathrm{Al}_{30}$-mer: $92 \%$ of the total aluminium content). ${ }^{18-20}{ }^{27} \mathrm{Al}$ solution spectroscopy also demonstrated the absence of soluble aluminium species in aluminium hydroxide suspensions. Aqueous chicken egg white lysozyme and bovine serum albumin (BSA) solutions containing $50 \mathrm{mg} \mathrm{ml}^{-1}$ protein were prepared by dissolving the protein powder (Sigma) in distilled deionized water shortly before use.

Aluminium-protein systems were prepared at room temperature according to the procedure described previously. ${ }^{15}$ The final aluminium concentration was $0.15 \mathrm{~mol} \mathrm{~L}^{-1}$, the protein concentration being varied from 0 to $25 \mathrm{mg} \mathrm{mL}^{-1}$ (equivalent to 0 to $1.7 \mathrm{mmol} \mathrm{\textrm {L } ^ { - 1 }}$ protein) in steps of $2.5 \mathrm{mg}$ $\mathrm{mL}^{-1}$. The range of lysozyme : aluminium molecular concentration ratios used was $1: 67.8$ to $1: 6.8$ for lysozyme : $\mathrm{Al}_{13}$-mers, $1: 29.4$ to $1: 2.9$ for lysozyme : $\mathrm{Al}_{30}$-mers and $1: 0.092$ to $1: 0.009$ for lysozyme : aluminium hydroxide particles (evaluated from the approximation of $100 \mathrm{~nm}$ diameter and $10 \mathrm{~nm}$ height cylindrical hydroxide particles, having a density of $0.3 \mathrm{~g} \mathrm{~cm}^{-3}$ ).

The series of aluminium-protein containing samples were analyzed after solutions had been aged for $24 \mathrm{~h}$ using a range of solution and colloidal techniques. After careful centrifugation of the insoluble part of the samples, the precipitated solid was freeze-dried and analyzed using solid-state techniques.

\section{Solutions /colloids characterisation}

All the solution characterisation procedures used throughout these studies have been used and described in detail in previous publications from our group. Briefly, ${ }^{27} \mathrm{Al}$ solution NMR spectra were acquired using a Jeol ECX400 spectrometer (Jeol, Tokyo, Japan) operating with a $\mathrm{D}_{2} \mathrm{O}$ lock, single pulse method, X-pulse of $9.4 \mu \mathrm{s}, 512$ scans, relaxation delay $0.5 \mathrm{~s}$. Quantification of the spectra was carried out using a peakfitting algorithm. ${ }^{18,19}$

The free protein concentrations in the systems were determined after centrifugation at $3000 \mathrm{rpm}$ for $10 \mathrm{~min}$ to remove any solids using a Thermo UV1 spectrophotometer for absorbance measurement. A Bradford total protein assay was used for protein quantification. ${ }^{21}$

The $\mathrm{pH}$ and conductivity of the systems were measured with a PHM-250 pH-meter with Red Rod glass electrode and a temperature sensor, and a CDM-230 conductivity meter with two-plate conductivity probe and a temperature sensor (all from Radiometer Analytical). Viscosity was measured with an AND SV-10 vibro-viscometer (AND A\&D Ltd., Tokyo, Japan) with gold-coated transducer and temperature sensor.
Dynamic light scattering (DLS) and zeta potential measurements of aluminium species-protein solutions were acquired using a Zetasizer Nano $\mathrm{S}$ from Malvern Instruments (Worcestershire, UK).

\section{Preparation of solid materials, scanning electron microscopy}

After centrifugation of the samples the resulting 'solid' materials were rinsed with water and centrifuged again. The pellet obtained was subsequently freeze-dried for $24 \mathrm{~h}$ using a Virtis freeze-drier before being mounted on Scanning Electron Microscope (SEM) stubs (TAAB) and coated with carbon using a standard procedure. A JSM-840A SEM (JEOL) operating at an acceleration voltage of $25 \mathrm{keV}$ and a working distance of $15 \mathrm{~mm}$ was used throughout the studies.

\section{Comparative Fourier transform infrared (FTIR) study of protein conformation in the presence of aluminium species}

In order to comparatively study the variation of protein conformation upon addition of the inorganic species to lysozyme and bovine serum albumin, a series of model aluminium-BSA and aluminium-lysozyme solutions were prepared similarly to the variable protein concentration samples, by maintaining the protein concentration at $1.7 \mathrm{mmol} \mathrm{L}^{-1}$ and varying the aluminium concentration from 0 to $0.15 \mathrm{~mol} \mathrm{~L}^{-1}$ by steps of $0.015 \mathrm{~mol} \mathrm{~L}^{-1}$, leaving the samples to age for $24 \mathrm{~h}$ before freeze-drying for infrared spectroscopic analysis.

For spectroscopic characterization of the resulting samples a standard $\mathrm{KBr}$ disc technique was used, $2 \mathrm{mg}$ of freeze dried sample being mixed with $198 \mathrm{mg}$ of $\mathrm{KBr}$ (Aldrich, IR grade, $99 \%$ ) and pressed into a disc at $\sim 10$ tons $\mathrm{cm}^{-2}$ pressure. Spectra were recorded at $2 \mathrm{~cm}^{-1}$ resolution, the interferometer speed set to $0.4747 \mathrm{~cm}^{-1} \mathrm{~s}^{-1}, 128$ scans being averaged for each spectrum.

Two different techniques were applied in order to understand the molecular characteristics of the aluminium speciesprotein interactions, and to evidence variations in the biomolecules structure and chemical properties, which can potentially lead to drastic changes in their activity. The amide I group of backbone $\mathrm{C}=\mathrm{O}$ vibrations was firstly used to obtain an assessment of protein conformation as a function of aluminium species concentration.

Spectra were truncated between 1800 and $1375 \mathrm{~cm}^{-1}$, before applying a multiplicative scatter correction (MSC, GRAMS 32) to groups of spectra obtained for each aluminium speciesprotein system. Random noise and minor components were removed by use of a factor analysis algorithm (Minitab 14), conserving only the principal components ( 5 in all cases) for the reconstruction of the spectra, on the basis of their respective contribution to the original data.

For secondary structure assessment, the smoothed and base-lined spectra were used between 1720 and $1490 \mathrm{~cm}^{-1}$ (amide I and II bands). Both bands were deconvoluted using an automated curve fitting routine programmed using MatLab software. Peak positions corresponding to different structural elements of the two proteins were obtained from the literature, ${ }^{22,23}$ their variation being limited to $\pm 2 \mathrm{~cm}^{-1}$ during the fit. 6 peaks were fitted to the amide I feature, corresponding to vibrations attributed to side chains vibrations $\left(1613 \mathrm{~cm}^{-1}\right)$, 
$\beta$-sheets $\left(1620 \mathrm{~cm}^{-1}\right), \beta$-strands $\left(1630 \mathrm{~cm}^{-1}\right)$, random coils $\left(1646 \mathrm{~cm}^{-1}\right), \alpha$-helices $\left(1654 \mathrm{~cm}^{-1}\right)$ and turns/H-bonded COOH $\left(1680-1690 \mathrm{~cm}^{-1}\right)$.

2D Correlation analysis was carried out by using a MatLab toolbox ${ }^{24}$ written on the basis of the original work by Noda and Ozaki. ${ }^{25}$

\section{Results and discussion}

\section{Macroscopic measurements: $\mathrm{pH}$, conductivity and viscosity of the systems}

Aspartic and glutamic acids have been demonstrated to bear the highest affinity for aluminium species in previous studies of aluminium-biomolecule interactions. Lysozyme only displays 6-7 of those acidic residues at its surface and exhibits a large positive charge at the $\mathrm{pH}$ considered, making the approach of the highly positively charged aluminium species difficult, and charge cancellation almost non-existent. Indeed $\mathrm{pH}$, conductivity and viscosity measurements of the samples prepared from aluminium species and lysozyme did not show large changes (ESI $\dagger$ ) as those observed in the presence of BSA, due to the lower acidic residue content of the protein. In particular, the $\mathrm{pH}$ remained within the domain of stability of the aluminium species $(\mathrm{pH} \sim 4.2-4.4$, Fig. $\mathrm{S} 1, \mathrm{ESI} \dagger){ }^{18,19}$

Both aluminium polyoxocation-containing systems $\left(\mathrm{Al}_{13}-\right.$ lysozyme and $\mathrm{Al}_{30}$-lysozyme) showed no significant increase of viscosity whatever the lysozyme concentration (viscosity values remained close to that of pure water and lysozyme solution at $1.00 \pm 0.29 \mathrm{cP}$ ), indicating little or no gelation for the systems in question. In contrast, the viscosity of the aluminium hydroxide-lysozyme mixtures increased $\sim 7 \%$ upon lysozyme addition, demonstrating limited gelation.

\section{Dynamic light scattering and zeta potential measurements}

Evidence for the formation of bioinorganic assemblies is provided by the results of dynamic light scattering, where an evolution in the particle size of the model aluminiumlysozyme systems (Fig. 1) was observed.

In the case of samples prepared from the aluminium hydroxide sol, the measured particle sizes increased steadily, from 110 to $129 \mathrm{~nm}$ with increasing lysozyme concentration (Fig. 1(A)).
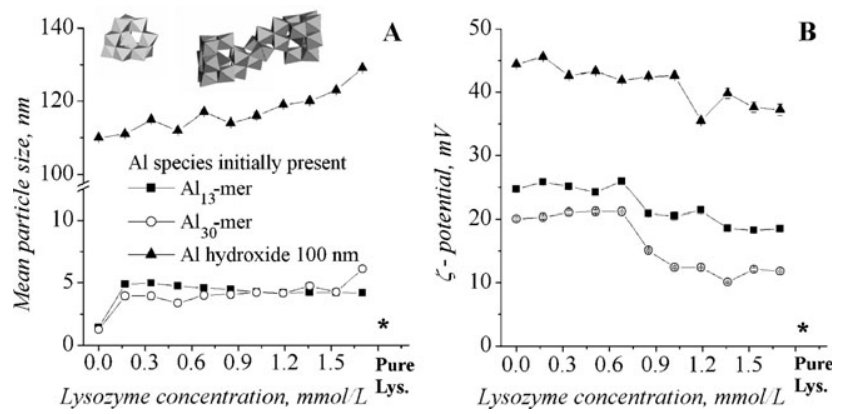

Fig. 1 Polygonal representation of $\mathrm{Al}_{13}$ and $\mathrm{Al}_{30}(\mathrm{~A})$ and evolution of (A) average particle sizes measured by dynamic light scattering (B) zeta-potential of aluminium species-lysozyme samples as a function of lysozyme concentration. Particle size R.S.D. $<0.3 \%$ (measurements in triplicate). The particle size and zeta potential measured for pure lysozyme are presented as stars for comparison.
Similarly to what has been found from analogous studies using bovine serum albumin, ${ }^{15}$ lysozyme probably covers the surface of aluminium hydroxide particles, but is however not inducing an electrostatically driven coagulation due to its positive charge in the $\mathrm{pH}$ domain considered. As follows from Fig. 1, the particle size of the pure $\mathrm{Al}_{13}$-mer and $\mathrm{Al}_{30}$-mer solutions was found to be close to the actual sizes of these species $(1 \pm 0.1$ and $2 \pm 0.05 \mathrm{~nm}$, respectively $\left.{ }^{6}\right)$. Once lysozyme was added, the average particle size in all cases increased to $5.18 \pm 0.40$ and $6.13 \pm 0.38 \mathrm{~nm}$, respectively. For both aluminium polyoxocation-lysozyme samples the mean size of the suspension did not change with further increase of lysozyme concentration. The mean diameter of the lysozyme in solution as measured by DLS was $\sim 1 \mathrm{~nm}$ (although from the literature the size of the lysozyme molecule is $3 \times 3 \times 4.50 \mathrm{~nm}^{26,27}$ ). The mean particle size of aluminium polycation-lysozyme samples probably arises from some limited adsorption of polycation clusters onto an area of the "surface" of lysozyme that carries some negative charges under mildly acidic conditions ${ }^{28}(\mathrm{pH}<5)$, thus allowing the protein to be "seen". Given that the ratio of aluminium to protein decreases as the protein concentration in solution increases and yet the mean particle size remains the same it would suggest that the DLS technique is measuring a specific molecular complex which, given the fact that the lowest $\mathrm{Al}_{n}$ : protein ratio used is $3: 1$, is likely to be formed from 1 lysozyme for $3 \mathrm{Al}_{30}$ or 1 lysozyme for 6-7 $\mathrm{Al}_{13}$, the ratio matching is this case the number of carboxylic acid moieties available at the surface of the lysozyme molecule.

The hypothesis above is supported by zeta-potential measurements of the model systems in question (Fig. 1(B)). The zeta-potential value for the aluminium polyoxocation-lysozyme system is positive at all lysozyme concentrations measured, $\mathrm{Al}_{13}$-containing samples having higher zeta-potential values than $\mathrm{Al}_{30}$-containing samples. In pure solutions of similar concentration, free lysozyme molecules bear a potential of $2 \pm 0.80 \mathrm{mV}$ at $\mathrm{pH}$ 4. The observed charge evolution can be explained by the adsorption of aluminium polyoxocations on the surface of the protein. For small additions of lysozyme, the potential observed is that for the free aluminium polycations alone, however as more and more lysozyme is added, the amount of free aluminium polycations is progressively reduced in comparison to the aluminium associated with the lysozyme-polycation conjugates, and the potential slowly decreases to reach a value corresponding to that of a lysozyme-polycation species.

For aluminium hydroxide, the value of the zeta-potential is approximately twice as high as that of the aluminium polyoxocation-lysozyme solutions at similar concentrations and decreases with increasing amounts of lysozyme. The protein is probably adsorbed on the colloid surface, leading to a decrease in zeta-potential produced by a compensation of some of the positive charge of the surface by the negatively charged groups of the protein, together with a masking of the hydroxide particles potential by the less charged biomolecules. ${ }^{11}$

\section{Residual concentrations of free lysozyme}

To clarify the extent of aluminium species-lysozyme association after aging of the samples, free lysozyme concentrations 


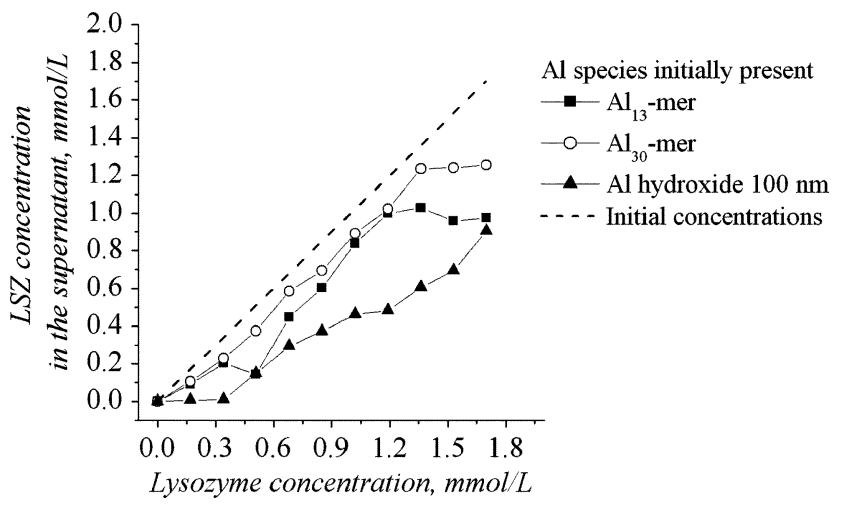

Fig. 2 Free lysozyme concentration in the supernatant solutions of the aluminium species-lysozyme samples after centrifugation.

were measured as a function of lysozyme concentration after removal of the insoluble matter by centrifugation (Fig. 2).

The amount of protein remaining in solution reflects phenomena such as adsorption to colloidal particles or electrostatic stabilisation of the protein by binding to strongly positive ions such as $\mathrm{Al}_{13}$-mer and $\mathrm{Al}_{30}$-mer. Therefore, residual protein concentration gives additional insights into the formation of colloidal, self-assembled composites.

The residual solution lysozyme concentration observed was lower than that added to the solutions (dotted line) for all the samples analysed.

The reduction of free lysozyme in solution was more pronounced for aluminium hydroxide-lysozyme systems due to the larger size of the particles to which the protein is bound, therefore enhancing the removal of the protein from solution on centrifugation.

In the case of aluminium polycation-lysozyme systems, lysozyme concentration reached a plateau above $1.19 \mathrm{mmol}$ $\mathrm{L}^{-1}$ protein added. The protein concentration observed for this plateau was higher in the presence of $\mathrm{Al}_{30}(\sim 1.19 \mathrm{mmol}$ $\left.\mathrm{L}^{-1}\right)$ than in the presence of $\mathrm{Al}_{13}\left(\sim 1.02 \mathrm{mmol} \mathrm{L}^{-1}\right)$. This difference is probably attributable to the differing stability of aluminium polycations-lysozyme assemblies, $\mathrm{Al}_{30}$-lysozyme being the most stable species due to the higher charge and stability of $\mathrm{Al}_{30}$-mer compared with $\mathrm{Al}_{13}$-mer.

\footnotetext{
${ }^{27} \mathrm{Al}$ solution NMR

${ }^{27} \mathrm{Al}$ solution NMR spectroscopy was used to investigate the stability of the polycations in the presence of the protein. ${ }^{6,19,27} \mathrm{Al}$ NMR spectra acquired from the $\mathrm{Al}_{13}$-lysozyme solutions show peaks at $\sim 63 \mathrm{ppm}$ (tetrahedral core of the $\mathrm{Al}_{13}$-mer) and $\sim 0 \mathrm{ppm}$ (octahedral signal of aluminium monomers) along with a signal at $80 \mathrm{ppm}$ arising from aluminate ions of the internal reference solution (Fig. 3(A)). ${ }^{29}$ In the spectra of the $\mathrm{Al}_{30}$-mer-lysozyme systems (Fig. 7(B)), along with the above mentioned signals at $\sim 63$ and $\sim 0 \mathrm{ppm}$, a broader signal at $70 \mathrm{ppm}$ was observed, which corresponds to the tetrahedral "core" aluminium nuclei of the $\mathrm{Al}_{30}$-mer. ${ }^{30}$

Very little difference was observed between the samples with 'Al' alone and with the highest concentration of protein again producing evidence for a much weaker interaction of lysozyme
}
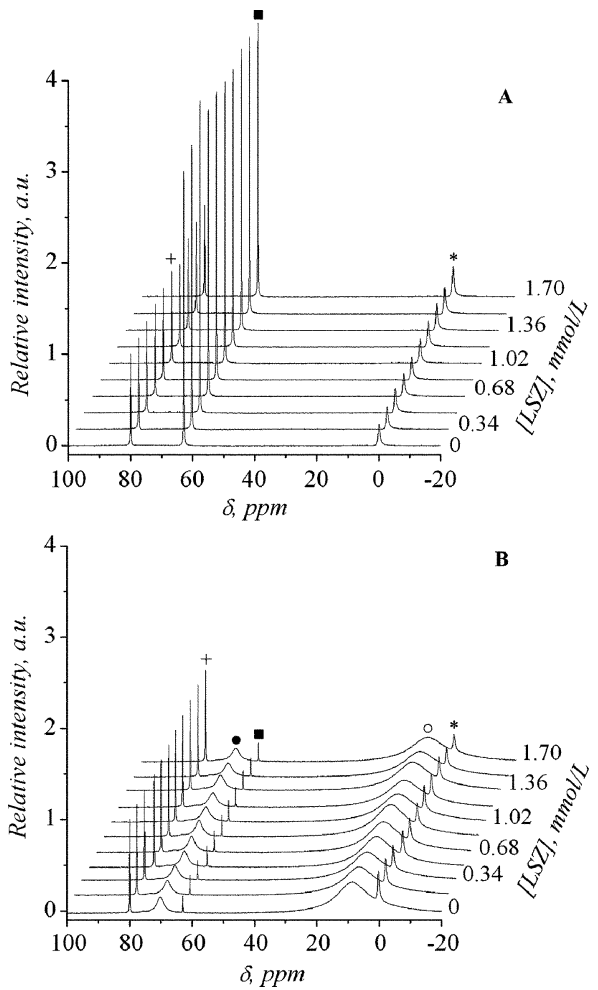

Fig. $3{ }^{27} \mathrm{Al}$ solution NMR spectra of the $\mathrm{Al}_{13}$-mer-lysozyme $(T=$ $\left.25^{\circ} \mathrm{C}\right)(\mathrm{A})$ and $\mathrm{Al}_{30}$-mer-lysozyme $\left(T=60{ }^{\circ} \mathrm{C}\right)(\mathrm{B})$ samples, showing peaks attributed to $*$ monomeric aluminium in octahedral environment, + monomeric aluminium in tetrahedral environment (reference solution), $\mathbf{\square}$ aluminium in the tetrahedral environment of $\mathrm{Al}_{13}$ tetrahedral cores, $\bullet, \bigcirc$ aluminium, respectively in the tetrahedral environment of $\mathrm{Al}_{30}$ cores and the octahedral environment of $\mathrm{Al}_{30}$ shells.

with $\mathrm{Al}$ species than with BSA, which did lead to important modifications in the NMR signal. ${ }^{15}$

\section{Scanning electron microscope observations}

The solid products obtained by freeze-drying of various aluminium species-lysozyme samples were subjected to SEM analysis to observe the morphology of the prepared materials (Fig. 4). In the case of pure $\mathrm{Al}_{13}$-mer and $\mathrm{Al}_{30}$-mer systems, the freeze-dried material was disorganized, although recurrently, flake-shaped materials were observed. Upon lysozyme addition, the samples containing $\mathrm{Al}_{13}$-mers changed progressively until finally they acquired a Velcro-like structural appearance for samples prepared in the presence of $1.7 \mathrm{mmol} \mathrm{L}^{-1}$ of lysozyme. For the $\mathrm{Al}_{30}$-mer-based materials, the solid products obtained tended to organize themselves into structures characterized by sheets covered with equally spaced parallel ribbons (Fig. 4). The $100 \mathrm{~nm}$ aluminium hydroxide-based samples exhibited, in the absence and in presence of lysozyme, a morphology similar to the one observed for the $\mathrm{Al}_{30}$-mer-lysozyme samples.

The reason for the "nanoribbon-sheet" morphology observed in the $\mathrm{Al}_{30}$-mers and aluminium hydroxide-containing samples is unclear. This morphology could arise from the freeze-drying procedure. Further morphological and spatial chemical analysis is required to explain this phenomenon. 


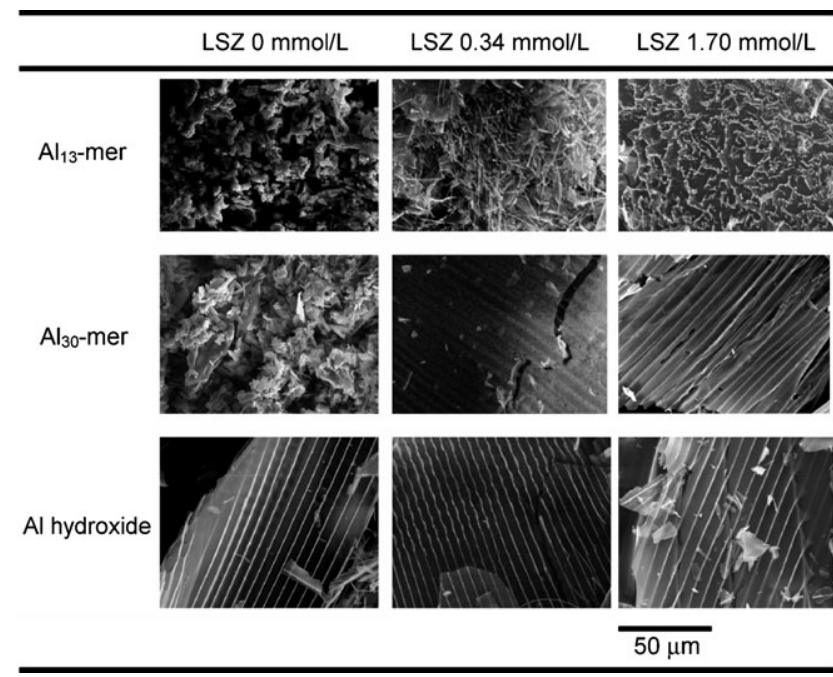

Fig. 4 SEM pictures of aluminium species-lysozyme hybrid materials prepared by freeze-drying.

\section{Comparative FTIR study of BSA and lysozyme/aluminium species systems}

Among amino acids, oxygen donors are usually the best aluminium ligands. The amino acids most likely to bind aluminium are thus $\mathrm{Asp}-\mathrm{COO}^{-}, \mathrm{Glu}_{-} \mathrm{COO}^{-}$or $\mathrm{Ser}-\mathrm{OH}$, $\mathrm{Thr}-\mathrm{OH}$ or $\mathrm{Tyr}-\mathrm{O}^{-}$. Aluminium interaction with proteins can cause conformational changes, or link peptide chains together through their carboxylates moieties. ${ }^{31}$ Both secondary structures and potential aluminium binding residues of BSA and lysozyme are shown in Fig. 5.

Both proteins are composed of a large amount of $\alpha$-helical and turn structures, a small amount of $\beta$-sheets being present in lysozyme (Fig. 5(A)-(C)). The BSA surface has a large number of strong possible binding sites, e.g. aspartic and glutamic acid residues, together with weaker binders, leading to a high negative surface charge under the $\mathrm{pH}$ range used in this study. In contrast the surface of lysozyme is mostly positive, and on average has much weaker binding sites for

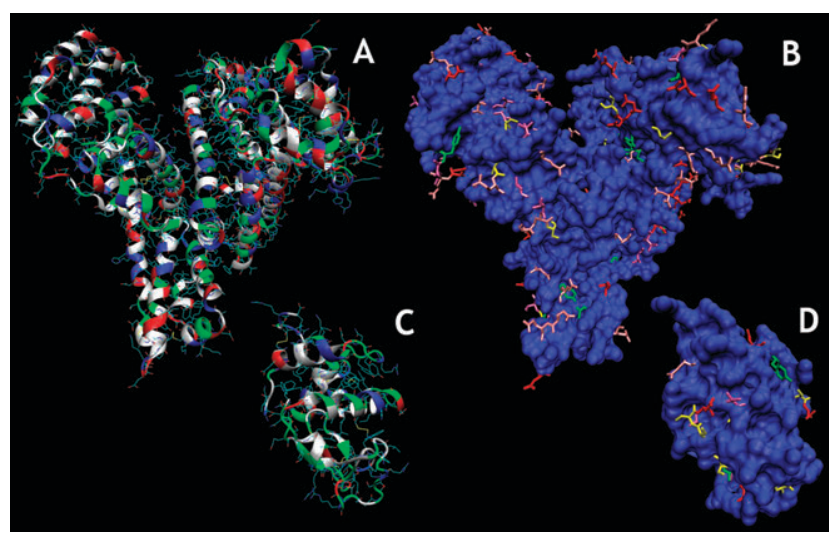

Fig. 5 Structures of BSA obtained through modelling using the SAM-T06 $\operatorname{server}^{32}$ (A, B) and lysozyme obtained from RCSB protein data bank file 2HU1 (C, D) showing the secondary structural motifs $(\mathrm{A}, \mathrm{C})$ and the surface residues prone to the binding of aluminium ions (B, D). Representation from Visual Molecular Dynamics software (VMD). ${ }^{33}$ aluminium than BSA. The close proximity of binding sites and the average negative surface charge of BSA will lead to a large electrostatic potential in different points of the molecule that will favour the approach and binding of aluminium species, whereas the proximity of positively charged moieties will weaken the electrostatic field surrounding lysozyme, and thus disfavour binding.

In order to evidence these two different interaction tendencies, a comparative study of BSA and lysozyme in the presence of aluminium species was carried out using FTIR spectroscopy for the characterisation of samples prepared at fixed protein concentration and varying aluminium species concentration.

No strong conformational changes were observed upon aluminium species addition for BSA or lysozyme (Fig. 6), apart from a slight decrease $(\sim 5 \%)$ in signal attributed to $\alpha$-helices upon aluminium polycations addition to BSA, and a decrease, also minimal, of the signal attributed to turns upon addition of aluminium polycations to lysozyme.

The main modification observed affects the sidechain vibrations, with a marked increase in the signal observed at 1613 $\mathrm{cm}^{-1}$ for the two proteins upon addition of $\mathrm{Al}_{13}$ and $\mathrm{Al}_{30}$. Upon increase in aluminium hydroxide concentration, the same signal increases for lysozyme and decreases for BSA.

These observations demonstrate that interactions between aluminium species and the two proteins influence mostly their sidechains without profoundly affecting their conformation. In order to obtain more information on the nature of these interactions, 2D correlation analysis was used.

In BSA/aluminium polycation synchronous correlation maps, most of the spectral modifications can be attributed to the perturbation of carboxylic acid moieties of the protein (aspartic and glutamic acid residues) by the introduction of aluminium species, with strong positive autopeaks and cross peaks at 1405 and $1600 \mathrm{~cm}^{-1}$. Small negative cross peaks are also present at $1740 / 1595$ and $1740 / 1405 \mathrm{~cm}^{-1}$ (Fig. 7(A) and (B)).

The peaks at 1740 and $1710 \mathrm{~cm}^{-1}$ can be attributed to the $\nu(\mathrm{C}=\mathrm{O})$ vibration of $\mathrm{COOH}$ groups that are very sensitive to hydrogen bonding. The vibration of unbound groups can be found at up to $1762 \mathrm{~cm}^{-1}$ and can shift below $1700 \mathrm{~cm}^{-1}$ for bound groups. ${ }^{34}$ Peaks in the 1400 and $1600 \mathrm{~cm}^{-1}$ regions are, respectively attributable to $\nu_{\mathrm{s}}\left(\mathrm{COO}^{-}\right)$and $\nu_{\text {as }}\left(\mathrm{COO}^{-}\right)$of the deprotonated Glu and Asp residues. These two vibrations are susceptible to shifts by $+60 /-40 \mathrm{~cm}^{-1}$ from $1402 / 1579 \mathrm{~cm}^{-1}$ for Asp and from $1404 / 1556 \mathrm{~cm}^{-1}$ for Glu upon deformations induced by cation chelation. Therefore the shift observed here demonstrates the binding of aluminium species to deprotonated Glu and Asp residues. Furthermore, the correlation of $\mathrm{COO}^{-}$groups with non $\mathrm{H}$-bonded $\mathrm{COOH}$ indicate that the interaction of $\mathrm{Al}_{13}$ and $\mathrm{Al}_{30}$ with Glu and Asp residues occurs mostly at the surface of the protein, without affecting the secondary structure of the molecule.

For BSA/aluminium hydroxide systems, positive autopeaks and cross peaks are observed at 1380, 1500 and $1710 \mathrm{~cm}^{-1}$ (Fig. 7(C)). The correlations attributable to the $\mathrm{COO}^{-}$groups are almost absent from the synchronous correlation diagram, and the signal from $\mathrm{H}$-bonded $\mathrm{COOH}$ is mostly positively correlated to a signal at $1500 \mathrm{~cm}^{-1}$, which is attributed to the $\delta(\mathrm{COH})$ vibrations of $\mathrm{COOH}$, a vibration known to strongly 

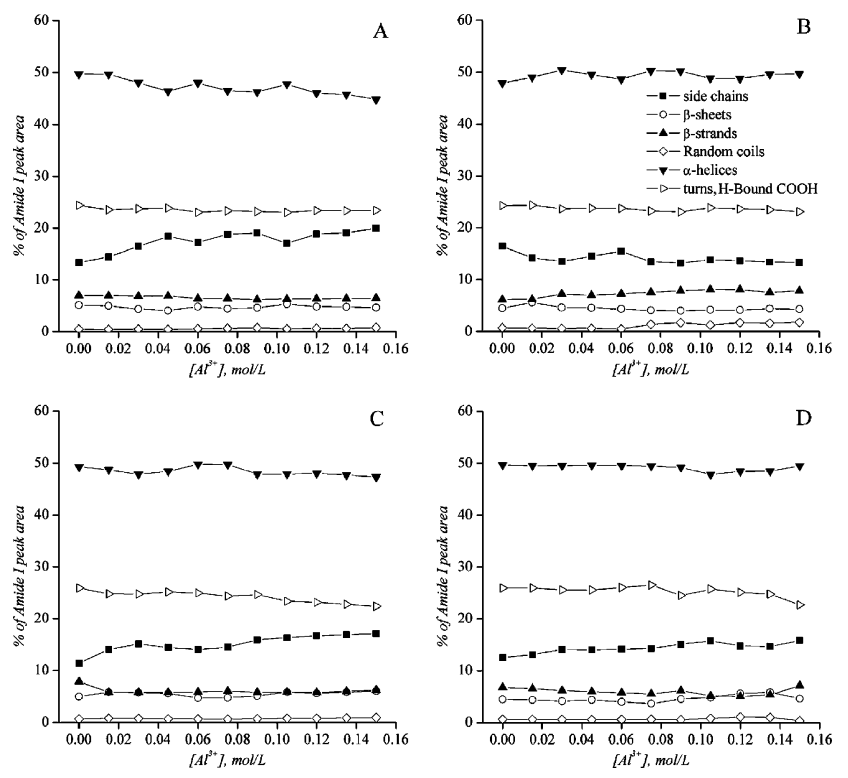

Fig. 6 Contribution of different amide vibration bands to the area of the amide I band, determined by means of peak fitting for samples prepared from $\mathrm{BSA}-\mathrm{Al}_{13}(\mathrm{~A}), \mathrm{BSA}-$ aluminium hydroxide (B), lysozyme- $\mathrm{Al}_{13}(\mathrm{C})$ and lysozyme-aluminium hydroxide (D) systems.

shift upon hydrogen bonding (1264-1450 $\left.\mathrm{cm}^{-1}\right) .{ }^{34}$ Deprotonated tyrosine ring vibrations can also be observed in this spectral region, but the correlation of their evolution with the signal from $\mathrm{COOH}$ groups cannot be readily explained.

The asynchronous correlation diagram is similar to the map obtained in the presence of the two polycations (Fig. 8), however the vibrations related to $\mathrm{COO}^{-}$groups correlate with more hydrogen bonded $\mathrm{COOH}$ groups. In addition, a correla- tion can be noticed between $\mathrm{COOH}$ groups being exposed to different hydrogen bonding modes. These two observations indicate that the presence of the hydroxide sol first perturbs the hydrogen bonding of $\mathrm{COOH}$ groups, or that $\mathrm{COOH}$ groups H-bond to the surface of the hydroxide before being deprotonated, this last step being however less likely than in the presence of polycations due to the large size and low flexibility of the hydroxide particles. A different correlation scheme is observed for lysozyme- - based samples, with a major autopeak at $1515 \mathrm{~cm}^{-1}$ in the presence of all aluminium species. Similarly to the case of aluminium hydroxide/BSA samples, this signal can be attributed to $\delta(\mathrm{COH})$ of $\mathrm{COOH}$ groups, this signal being positively correlated with a feature at $1695 \mathrm{~cm}^{-1}$, attributed to strongly $\mathrm{H}$-bonded $\mathrm{COOH}$, and negatively correlated with a feature at $1606 \mathrm{~cm}^{-1}$, attributable to $\nu_{\text {as }}\left(\mathrm{COO}^{-}\right)$vibrations. However no negative correlation can be noticed with the weaker $\nu_{\mathrm{s}}\left(\mathrm{COO}^{-}\right)$vibration. This signal can also be attributed to $\nu(\mathrm{CC})$ ring and $\delta(\mathrm{CH})$ of deprotonated Tyr residues, ${ }^{34}$ especially as asynchronous correlation is observed between features at 1475 and $1515 \mathrm{~cm}^{-1}$. These two latter signals could be, respectively attributed to complexing Tyr and protonated tyrosine, Tyr deprotonation leading to a characteristic shift of the $\nu(\mathrm{CC})$ ring and $\delta(\mathrm{CH})$ signal from 1500 to $1515 \mathrm{~cm}^{-1}$.

The signal at $1606 \mathrm{~cm}^{-1}$ is therefore attributed to $\nu(\mathrm{CC})$ ring and $\delta(\mathrm{CH})$ vibrations of the protonated residue. The correlation of the $1500-1515 \mathrm{~cm}^{-1}$ signals with the feature at $1695 \mathrm{~cm}^{-1}$ would be then attributable to a cooperative binding of aluminium species to Asp, Glu and Tyr residues (Fig. 9) leading to a deprotonation of the latter residue, the $\mathrm{p} K_{\mathrm{a}}$ of Tyr being far higher (10.2) than the $\mathrm{pH}$ used during our experiments.

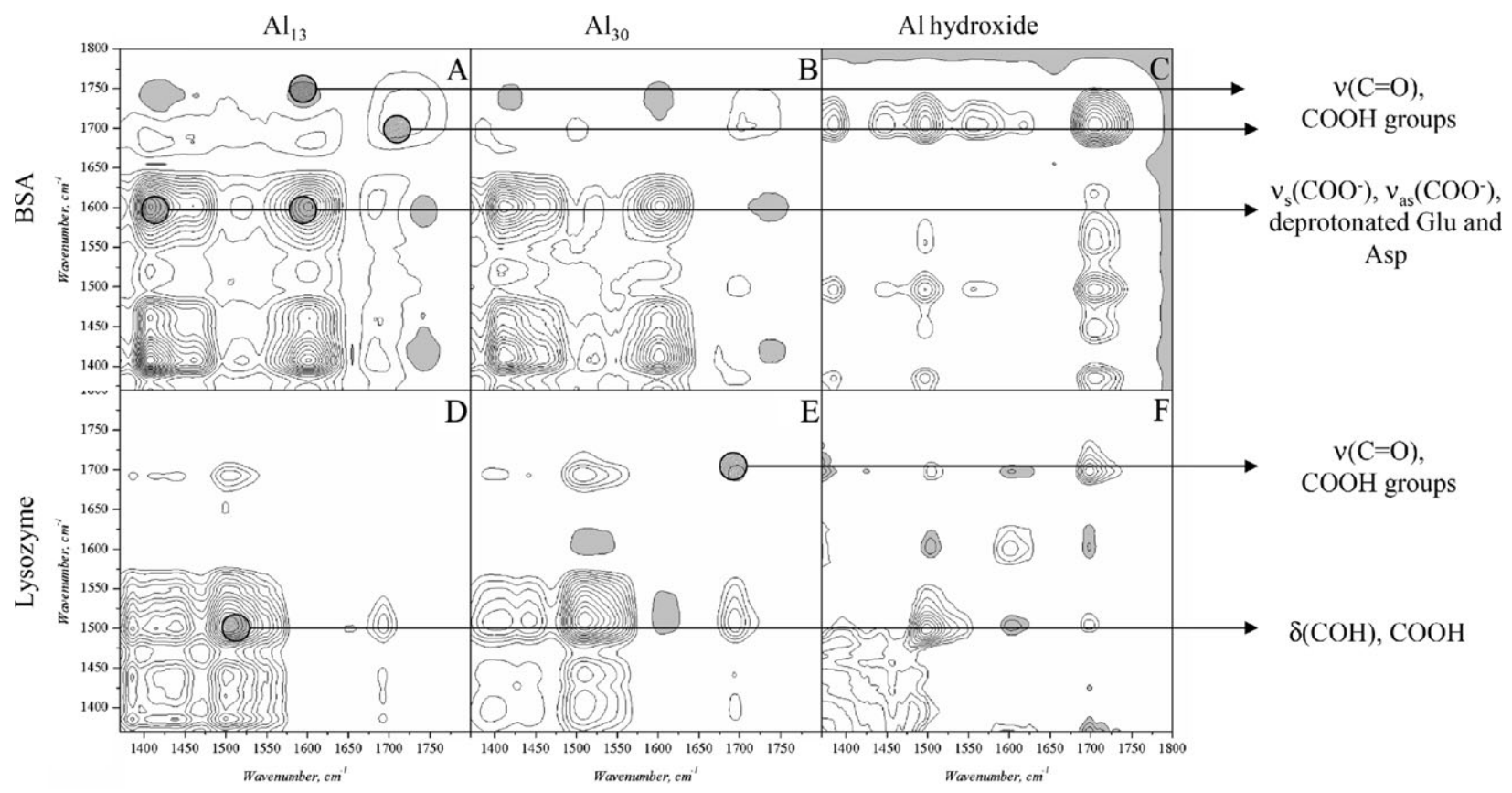

Fig. 7 Summary of synchronous 2D-COS maps generated from transmission FTIR spectra of samples prepared at different aluminium species concentrations in the presence of a constant concentration of protein. (A)-(C): $\mathrm{BSA}-\mathrm{Al}_{13}, \mathrm{BSA}-\mathrm{Al}_{30}$ and $\mathrm{BSA}-$ aluminium hydroxide; (D)-(F) lysozyme- $\mathrm{Al}_{13}$, lysozyme- $\mathrm{Al}_{30}$ and lysozyme-aluminium hydroxide. Areas of positive correlation are represented in white; areas of negative correlation are in grey. 


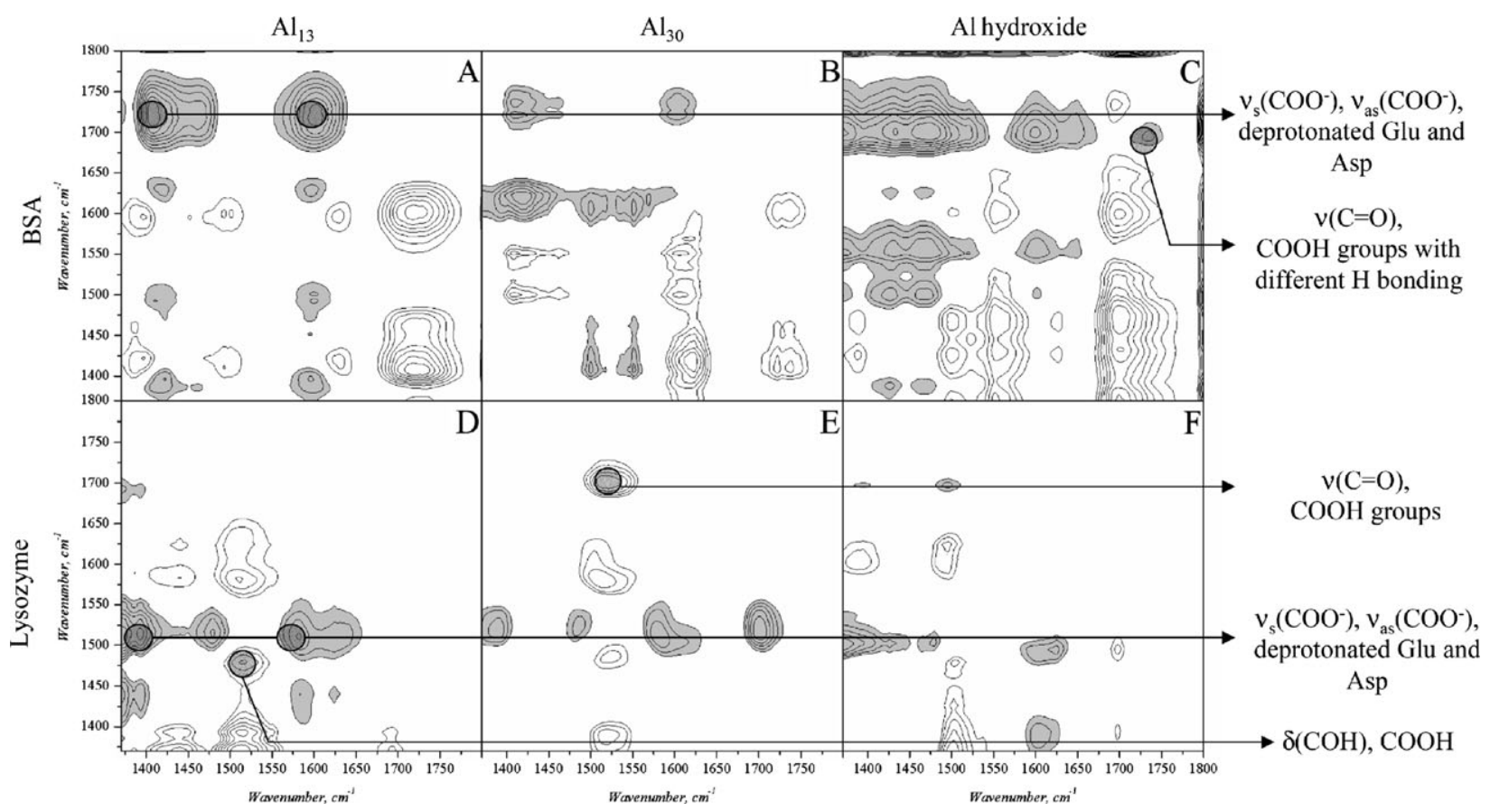

Fig. 8 Summary of asynchronous 2D-COS maps generated from transmission FTIR spectra of samples prepared at different aluminium species concentrations in the presence of constant concentrations of proteins. (A)-(C): $\mathrm{BSA}-\mathrm{Al}_{13}, \mathrm{BSA}-\mathrm{Al}_{30}$ and $\mathrm{BSA}-$ aluminium hydroxide; (D)-(F): lysozyme- $\mathrm{Al}_{13}$, lysozyme- $\mathrm{Al}_{30}$ and lysozyme-aluminium hydroxide. Areas of positive correlation are represented in white; areas of negative correlation are in grey.

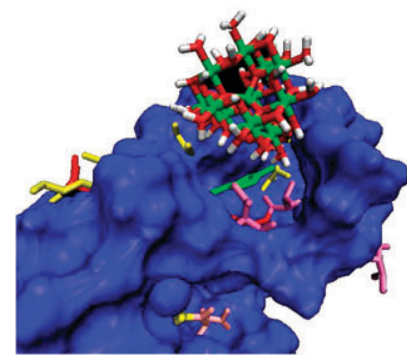

Fig. 9 Possible binding mode of $\mathrm{Al}_{13}$ to lysozyme, involving one tyrosine residue and other residues favourable to binding in the $\beta$-sheet region. Representation using $\mathrm{VMD}^{33}$ after energy minimisation and 5 ps MD equilibration of the assembly using Accelrys MS Discover and the Compass generalised force field. Colour codes: Tyr in green, Glu in pink, Asp in red, Ser in yellow.

\section{Conclusions}

The interactions of lysozyme, a biomolecule present in human and animal body fluids, with different aluminium species have been studied.

The results from FTIR analysis of aluminium species/protein systems demonstrated the likely interaction mechanisms leading to the formation of hybrid materials. For both BSA and lysozyme, the assembly of $\mathrm{Al}_{13}$ and $\mathrm{Al}_{30}$ with the proteins led to the formation of hybrid species observable by means of dynamic light scattering (particle size above the values obtained for both pure aluminium species and protein) and zeta potential measurements (potential stabilising to the value of the hybrid species upon increase in protein concentration).
However, the assembly of aluminium species with both proteins only led to a minor changes in their secondary structure, the main changes being observed for the protein surface groups as demonstrated from secondary structure quantification carried out for different protein : aluminium ratios. Polycations were demonstrated to bind Asp and Glu residues of BSA, leading to a deprotonation of their carboxylic acid groups, as demonstrated from 2D correlation spectroscopy. This deprotonation would have led to the increasing acidity of the solutions observed from $\mathrm{pH}$ measurements reported previously. ${ }^{15}$

In the case of lysozyme interacting with aluminium species, as well as for BSA interacting with aluminium hydroxide particles, only a perturbation of the hydrogen bonding of Asp and Glu $\mathrm{COOH}$ moieties can be noticed. This result demonstrates the weaker interaction of the soluble aluminium species with lysozyme, arising from the high positive electrostatic potential on the protein. The similarity of the interactions between aluminium hydroxide and both proteins is due to the rigidity and large dimensions of the colloid, which decreases the probability of contact between potential binding sites on protein and mineral surfaces. The correlations observed in the case of lysozyme could also demonstrate a cooperative binding of the aluminium species to acidic amino acids and tyrosine leading to a deprotonation of the later residue. This hypothesis will however require further experimentation to be confirmed. The variety of interactions observed between proteins bearing different physicochemical properties and aluminium species constitutes a useful base for the choice of polymers and biopolymers for the fabrication of novel aluminium-based materials, either from stable 
bioinorganic core-shell particles (comprising aluminium at the surface or in the bulk of the materials) or by self-assembly of composite networks having the ability to phase-separate from the initial liquid medium.

\section{References}

1. S. M. Bradley and R. A. Kydd, Catal. Lett., 1991, 8, 185-192.

2. E. Montarges, A. Moreau and L. J. Michot, Appl. Clay Sci., 1998, 13, $165-185$

3. J. Gregory and J. Duan, Pure Appl. Chem., 2001, 73, 2017-2026.

4. J. J. Fitzgerald and A. H. Rosenberg, in Antiperspirants and Deodorants, ed. K Laden, Marcel Dekker, New York, 1999, pp. $83-137$.

5. C. C. Perry and K. L. Shafran, J. Inorg. Biochem., 2001, 87, 115-124.

6. K. L. Shafran and C. C. Perry, Dalton Trans., 2005, 2098-2105.

7. J. P. Jolivet, From Solution to Solid State, Wiley and Sons, Chichester, 2000.

8. W. H. Casey, Chem. Rev., 2006, 106, 1-16.

9. G. Berthon, Coord. Chem. Rev., 1996, 149, 241-280.

10. W. R. Harris, G. Berthon, J. P. Day, C. Exley, T. Peder Flaten, W. F. Forbes, T. Kiss, C. Orvig and P. F. Zatta, J. Toxicol. Environ. Health, 1996, 48, 543-568.

11. K. Rezwan, L. P. Meier, M. Rezwan, J. Voros, M. Textor and L. J. Gauckler, Langmuir, 2004, 20, 10055-10061.

12. G. Furrer, B. L. Phillips, K.-U. Ulrich, R. Pöthig and W. H. Casey, Science, 2002, 297, 2245-2247.

13. D. R. Parker, T. B. Kinraide and L. W. Zelazny, Soil Sci. Soc. Am. J., 1989, 53, 789-796.

14. J. J. Comin, J. Barloy, G. Bourrie and F. Trolard, Eur. J. Agron., 1999, 11, 115-122.

15. O. Deschaume, K. L. Shafran and C. C. Perry, Langmuir, 2006, 22, 10078-10088.
16. E. Bergfors, B. Trollfors and A. Inerot, J. Allergy Clin. Immunol., 2004, 113, S294.

17. J. Berkowitz, M. A. Anderson and R. C. Graham, Water Res., 2005, 39, 3918-3928.

18. K. L. Shafran, O. Deschaume and C. C. Perry, J. Mater. Chem., $2005, \mathbf{1 5}, 3415-3423$.

19. K. Shafran, O. Deschaume and C. C. Perry, Adv. Eng. Mater., 2004, 6, 836-839.

20. P. M. Jardine and L. W. Zelazni, Soil Sci. Soc. Am. J., 1986, 895-900.

21. C. M. Stoscheck, Methods Enzymol., 1990, 182, 50-68.

22. T. J. Lenk, T. A. Horbett, B. D. Ratner and K. K. Chittur, Langmuir, 1991, 7, 1755-1764.

23. A. Muga, H. H. Mantsch and W. K. Surewicz, Biochemistry, 1991, 30, 7219-7224.

24. J. E. Berry and Y. Ozaki, 2D-CoS Toolbox, Matlab Code, Kwansei-Gakuin University, Uegahra, Japan, 2001.

25. I. Noda, A. E. Dowrey, C. Marcott, G. M. Story and Y. Ozaki, Appl. Spectrosc., 2000, 54, 236A-248A.

26. W. G. Burton, K. D. Nugent, T. K. Slattery, B. R. Summers and L. R. Snyder, J. Chromatogr., 1988, 443, 363-379.

27. A. A. Vertegel, R. W. Siegel and J. S. Dordick, Langmuir, 2004, 20, 6800-6807.

28. K. Rezwan, L. P. Meier and L. J. Gauckler, Biomaterials, 2005, 26, 4351-4357.

29. J. W. Akitt, J. Chem. Soc., Faraday Trans. 2, 1986, 82 , 377-379.

30. L. Allouche, C. Gerardin, T. Loiseau, G. Ferey and F. Taulelle, Angew. Chem., Int. Ed., 2000, 39, 511-514.

31. P. Rubini, A. Lakatos, D. Champmartin and T. Kiss, Coord. Chem. Rev., 2002, 137-152.

32. G. Shackelford and K. Karplus, Proteins: Struct., Funct., Bioinform., 2007, 69, 159-164.

33. W. Humphrey, A. Dalke and K. Schulten, J. Mol. Graphics, 1996, 14, 33-38.

34. A. Barth, Prog. Biophys. Mol. Biol., 2000, 74, 141-173. 